\title{
UNA APROXIMACIÓN AL ANÁLISIS DE LAS CADENAS MIGRATORIAS EN ESPAÑA A PARTIR DE LA ENCUESTA NACIONAL DE INMIGRANTES
}

\section{An Approach to the Analysis of Migratory Chains in Spain from the National Immigrant Survey}

\section{RICARDO GAETE QUEZADA}

Universidad de Antofagasta - Chile

\section{CARMEN RODRÍGUEZ SUMAZA}

Universidad de Valladolid - España

\section{RESUMEN}

En este trabajo se analizan los resultados de la Encuesta Nacional de Inmigrantes aplicada en España desde la perspectiva de las cadenas migratorias como paradigma explicativo de los procesos migratorios en el país.

En la primera parte se ofrece una revisión bibliográfica de los principales aspectos del concepto de cadenas migratorias. En la segunda, se identifican y analizan algunas variables indicativas de la existencia de cadenas migratorias en el proceso inmigratorio español reciente, tales como: contactos previos del inmigrante, influencia de los contactos en la decisión de viajar, envío de remesas, los contactos del inmigrante en el país de origen, y la intención de traer familiares.

Palabras clave: Cadenas migratorias, inmigración en España, demografía, Encuesta Nacional de Inmigrantes, paradigma relacional.

\section{ABSTRACT}

This paper focuses on the First National Immigrant Survey in Spain from the perspective of the migratory chains as an explanatory paradigm of migration processes in the country. The first part provides a literature review of key aspects of the concept of migratory chains. In the second part, we identify and discuss the survey results related to migratory chains, such as: contacts in Spain before arrival, influence of contacts in the decision to travel, money transfer, contacts in the immigrant's home country and intention of bringing relatives.

Key words: Migratory chains, immigration in Spain, demography, National Immigrant Survey, relational paradigm. 


\section{INTRODUCCIÓN}

La llegada masiva de inmigrantes hasta España es un proceso relativamente nuevo para este país, pasando de ser una nación netamente generadora de emigrantes hasta mediados de los setenta hacia una fuertemente receptora de inmigrantes, que ha visto ingresar a través de sus fronteras un creciente saldo inmigratorio en un período muy corto de tiempo.

El inicio del cambio de tendencia de la migración en España es fechada por algunos autores a partir de 1975 (Colectivo IOÉ, 1999 y 2003; Arango, 2004; Moreno, 2007), con un progresivo y aun más rápido aumento de las entradas netas de población desde mediados de los años noventa. Se trata de un fenómeno que está siendo ampliamente analizado desde el ámbito económico, político, social, cultural, etc. debido a las implicancias e importantes efectos que tiene para el desarrollo del país.

En virtud de los crecientes saldos migratorios acogidos por España en los últimos años, el Instituto Nacional de Estadísticas (INE) a partir del año 2007 diseña y aplica la Encuesta Nacional de Inmigrantes (ENI), para proporcionar información sobre las características sociodemográficas de los extranjeros residentes, así como respecto del establecimiento y composición del grupo familiar de los inmigrantes, considerando como principales variables de análisis de este fenómeno demográfico la edad, el género, lugar de nacimiento y procedencia, composición y características de la vivienda, relación con el ámbito laboral, educacional y social de los inmigrantes.

El presente artículo pretende realizar un análisis de los resultados obtenidos por la ENI, desde la perspectiva del concepto de cadenas migratorias como factor explicativo de la inmigración hacia España. En la primera parte se analizan algunos elementos teóricos relacionados con el concepto de cadenas migratorias y el paradigma relacional desde el que se aborda el tema.

En la segunda parte se revisa la cronología reciente del proceso migratorio en España y se seleccionan y analizan, de entre todas las variables de la ENI, una serie de indicadores de cadenas migratorias, concretamente las relativas a los contactos del inmigrante al momento de viajar, los contactos con familiares y/o amigos en el país de origen, el envío de remesas y la intención de traer a familiares en el futuro.

\section{EL PARADIGMA RELACIONAL COMO MARCO INTERPRETATIVO DE LA INMIGRACIÓN Y LAS CADENAS MIGRATORIAS COMO EXPRESIÓN DE DICHO PARADIGMA. ASPECTOS CONCEPTUALES}

De forma histórica ${ }^{1}$ y predominante se han venido explicando los procesos de migración fundamentalmente a partir de la prevalencia de problemas económicos en las sociedades 
de origen y como el resultado fundamental de decisiones individuales, deliberadas y racionales de los sujetos en un intento de mejorar su situación.

Estas teorías, eminentemente unidimensionales y limitadas, han sido paulatinamente reemplazadas por paradigmas y marcos interpretativos más orientados al reconocimiento de la importancia y papel de los grupos sociales en las decisiones de emigración y en los procesos de asentamiento, y también a la visualización del rol de los parientes y amigos en las decisiones migratorias. Son en este sentido especialmente clarificadores los trabajos de revisión de las explicaciones sobre las migraciones realizados, entre otros, por Portes \& Böröcz (1998); Massey et al. (1998); Blanco (2000) y Aparicio \& Tornos (2005).

Frente a las interpretaciones clásicas, predomina actualmente la idea de que los procesos de inmigración no se explican sólo por el incentivo del Estado para reclutar mano de obra inmigrante, o por la decisión personal de un individuo de probar suerte en el extranjero en busca de una mejor situación económica, sino que en un porcentaje importante de los procesos migratorios intervienen de forma ciertamente significativa otros sujetos más o menos próximos al potencial emigrante y que le proveen de información y de ayuda (Gurak \& Caces, 1998; Massey et al., 1998; Blanco, 2000; Malgesini \& Giménez, 2000; Aparicio \& Tornos, 2005; Moreno, 2007; Pascual de Sans, 2007; Cebolla \& González, 2008; González, 2008).

La evolución del análisis e investigación de los procesos migratorios hacia paradigmas y modelos relacionales y no puramente individuales o estructurales orienta los estudios de la migración hacia el tema de las redes sociales de los inmigrantes. El estudio del papel de "esos 'otros' posibilitadores de las migraciones" 2 sitúa este enfoque en el nivel de los denominados procesos sociales intermedios.

Esta perspectiva de análisis meso, que resulta 'crucial' según Faist (2000), se centra en la importancia de las redes sociales de ayuda e información en las migraciones, en el capital social de los potenciales emigrantes de cara a explicar sus estrategias migratorias.

En el análisis de los procesos migratorios mediante el paradigma relacional, una de las variables importantes de analizar en la inmigración se relaciona con el establecimiento de una cadena migratoria, lo que "hace referencia a la transferencia de información y apoyos materiales que familiares, amigos o paisanos ofrecen al potencial inmigrante para decidir su viaje [...] pueden financiar en parte el viaje, gestionar documentación y empleo, conseguir alquiler de una vivienda, etc.". 3

Si el grueso de las migraciones se producen por "tracción" de nuevos inmigrantes, tal y como señalan Massey et al. (1998), el estudio de las denominadas cadenas migratorias ofrece grandes posibilidades para comprender un poco mejor el importante aumento de la presencia de inmigrantes en el caso español. 
Los primeros en referirse al concepto de cadena migratoria fueron los australianos MacDonald \& MacDonald en $1964,{ }^{4}$ quienes la definieron como "el movimiento por el cual los inmigrantes toman conocimiento de las oportunidades de trabajo existentes, reciben los medios para viajar y cómo solucionar la vivienda y la forma de emplearse inicialmente por sus relaciones sociales primarias con emigrantes anteriores".

Respecto del concepto de cadena migratoria, también es posible definirlas como el "conjunto de vínculos interpersonales que conectan a migrantes, migrantes antiguos y no migrantes en su área de origen y de destino a través de lazos de parentesco, amistad y comunidad de origen compartida", ${ }^{5}$ donde cada acto de la migración desarrollado mediante una cadena migratoria contribuye a la creación de capital social entre las personas con las cuales el nuevo inmigrante se relaciona.

Sin embargo, resulta inevitable reconocer que los términos de redes y cadenas "se mezclan en el espacio-tiempo", si bien el concepto de cadenas migratorias tiene un carácter más "lineal y temporal", 6 debido fundamentalmente a que los vínculos interpersonales asociados a las cadenas migratorias pueden ser vistos como la primera fase del desarrollo de redes sociales más o menos amplias y complejas de inmigrantes en la sociedad receptora.

De esta manera, las cadenas migratorias son mayoritariamente redes sociales informales "compuestas por la familia extensa, los amigos y los vecinos que continúan siendo en la sociedad posindustrial una fuente muy importante de compañerismo, soporte y ayuda mutua". ${ }^{7}$

El propio Instituto Nacional de Estadística español (2008: 7) considera el concepto de red migratoria informal en las definiciones metodológicas de la ENI, señalando que se trata de un:

Conjunto de relaciones sociales en la que está envuelto un inmigrante y que están a disposición a la hora de implementar sus estrategias migratorias, residenciales o laborales. Las redes migratorias están integradas por parientes del sujeto, por personas vinculadas al inmigrante por razones de amistad, paisanaje o de conocimiento. Las instituciones también pueden formar parte de estas redes y en tal caso serían redes formales.

Las cadenas migratorias son, por tanto, un subconjunto particular de redes migratorias que vinculan a migrantes, antiguos migrantes y potenciales migrantes o no migrantes en un proceso de un intercambio de información y soporte que reduce sustancialmente la incertidumbre y los costos afectivos y materiales del traslado y que facilita en un primer momento la inserción del emigrante en la sociedad de destino, siendo por ello especialmente explicativas de las decisiones de emigrar. 
En este sentido se expresan Massey et al. (1998) al señalar el papel dinamizador de las cadenas migratorias en las migraciones internacionales y la importancia de los vínculos que las constituyen para el entramado social posterior de los emigrantes.

De esta manera, la especial importancia que tienen en las migraciones internacionales los vínculos familiares queda de manifiesto en el hecho de que "aunque las redes de inmigrantes se extienden más allá de la familia, la centralidad de los lazos familiares en la facilitación y promoción de la migración internacional es un hecho indiscutible ${ }^{\prime \prime}$, destacando que la influencia de la familia en los procesos migratorios es determinante no sólo en la decisión de emigrar, sino también en el envío de remesas, la no emigración de algunos miembros de la familia o el regreso de primo-inmigrantes.

Desde un punto de vista estructural, las cadenas migratorias son iniciadas por los denominados "primo-inmigrantes", quiénes "tienden a ser, en una alta proporción, jóvenes adultos, frecuentemente solteros o no acompañados por sus cónyuges, parejas $\mathrm{u}$ otros miembros de la familia". ${ }^{9}$ Una vez que el primo-inmigrante se ha instalado en el país receptor, la cadena migratoria por lo general será continuada por otros inmigrantes derivados, entre los que se pueden encontrar a familiares, amigos, paisanos o conocidos, por lo que la cadena migratoria ejercerá el efecto de "tirar" de los siguientes inmigrantes que iniciarán viaje.

Una de las teorías que mejor permiten explicar la continuidad y persistencia de los flujos migratorios es la teoría de las redes entre inmigrantes, que comienzan a desarrollarse entre los primeros inmigrantes que se instalan en el país de destino y los potenciales emigrantes que se quedan en el lugar de origen del primo-inmigrante. Debido a que "estas relaciones interpersonales se deben a lazos familiares o de amistad, a la misma procedencia étnica o nacionalidad [...] la existencia de estas redes aumenta la probabilidad de que se den migraciones ya que facilita, abarata (reducen costo material y también psicológico) y disminuye el riesgo del movimiento de un país al otro". ${ }^{10}$

En la práctica esto se traduce en que los inmigrantes ya instalados en el país van "tirando de la cadena" para que otros familiares, amigos o conocidos tomen la decisión de emigrar de su país de origen, ayudándoles en muchas ocasiones con financiamiento para el viaje, trámite de permisos o documentación, información, alojamiento, alimentación o simplemente el tener alguien conocido con quien interactuar.

Esta importancia de las cadenas migratorias también se relaciona con la teoría de la causación cumulativa de los flujos, que plantea que el efecto de "tracción familiar" presente en la inmigración "independiza un tanto a los flujos de las oscilaciones de las coyunturas económicas y demanda unas políticas de inmigración menos exclusivamente dependientes de dichas coyunturas", 11 lo que en la práctica hoy nos plantea que la existencia de familiares y amigos en el extranjero le permite al inmigrante afrontar de 
mejor manera las consecuencias de la crisis económica o las políticas gubernamentales que buscan restringir la inmigración.

Los efectos de las cadenas migratorias identificados de manera precedente son ratificados por investigaciones acerca de los vínculos económicos y familiares de los inmigrantes peruanos y ecuatorianos en España: ${ }^{12}$

Las cadenas migratorias desempeñan un papel clave a la hora de financiar el viaje y los gastos iniciales de los que quieren emigrar [...] una parte importante de las remesas se utiliza para este cometido. También es habitual que los migrantes que ya están instalados en la sociedad de destino faciliten la entrada legal de los familiares, ya sea a través de la reagrupación familiar cuando se trata de los hijos, hermanos menores de edad o padres del migrante de referencia o bien gracias a la consecución de un contrato de trabajo.

Sin embargo, existe una delgada línea que separa los conceptos de cadena migratoria y redes sociales, siendo posible diferenciar a la redes sociales de inmigrantes por tratarse de "estructuras mayores, extendidas y relativamente afianzadas que desarrollan una dinámica propia, pudiendo incluso desprenderse de los estímulos y desestímulos de la sociedad receptora. Las redes varían según las características étnico-culturales y el contexto económico, social y político de la sociedad receptora", ${ }^{13}$ destacando que la inmigración es un fenómeno social colectivo y no exclusivamente individual, como las teorías neoclásicas de la inmigración han planteado.

El tejido de relaciones con familiares y amigos permite, asimismo, explicar la distribución espacial y la decisión de asentamiento de los inmigrantes dentro del territorio espacial de la sociedad receptora, lo que queda de manifiesto en diversas investigaciones que señalan que "este tipo de vínculos es el relativo a las cadenas migratorias clásicas: una vez que los pioneros han emigrado las redes se tejen progresivamente y retroalimentan la cadena migratoria", 14 donde la ausencia de estos nexos familiares puede pesar más que las posibilidades de encontrar trabajo.

En definitiva, las cadenas migratorias a las que alude este trabajo y las redes sociales de inmigrantes son de altísima importancia para lograr un mejor asentamiento de los flujos migratorios, especialmente debido a la existencia de procesos de ruptura del vínculo social relacionados con el desarrollo de la inmigración:

Los grupos de proximidad, la familia, los compañeros, el medio escolar o profesional, parecen por todas partes en crisis, dejando al individuo, sobre todo joven o ya mayor sin cónyuge y sin familia, extranjero o inmigrante, en una soledad que conduce a la depresión, o bien a la búsqueda de relaciones artificiales y peligrosas, como esos grupos cuyos líderes asientan su influencia en la fuerza y la agresividad. ${ }^{15}$ 
Ante la generalización de estos procesos de ruptura del vínculo social en las sociedades modernas, es especialmente estratégico conocer y trabajar por el desarrollo del capital social de los inmigrantes. En este sentido desde hace tiempo numerosas estrategias de intervención comunitaria apuntan a este tipo de iniciativas, como la defendida por Rivas Nina (1995).

\section{EL PROCESO INMIGRATORIO RECIENTE EN ESPAÑA}

España ha mantenido durante siglos una amplia tradición emigratoria que se explica históricamente por los vínculos coloniales con el continente americano y, ya bien entrado el siglo XX, por su situación sociopolítica y el diferencial de desarrollo económico respecto de otros países de la Europa occidental.

No es hasta el último cuarto del siglo XX cuando, en parte como resultado de la crisis económica que asoló en la década de los setenta al conjunto de los países europeos industrializados, y en parte como consecuencia del propio desarrollo económico de España, se reducen de forma significativa las salidas de población española y comienzan los retornos de españoles emigrados. Se agota así, en expresión de López de Lera (2006), el patrón migratorio clásico.

En la década de los noventa se asiste, en paralelo, a un nuevo fenómeno: el aumento y consolidación de los flujos de entrada de población extranjera (Gráfico 1). El balance final no deja lugar a dudas: España pasa de ser un país emigrante a otro receptor neto de inmigración internacional, ${ }^{16}$ siguiendo tendencias observadas con anterioridad en otros países de la OCDE.

Gráfico 1: Entradas según nacionalidad. 1980-2007

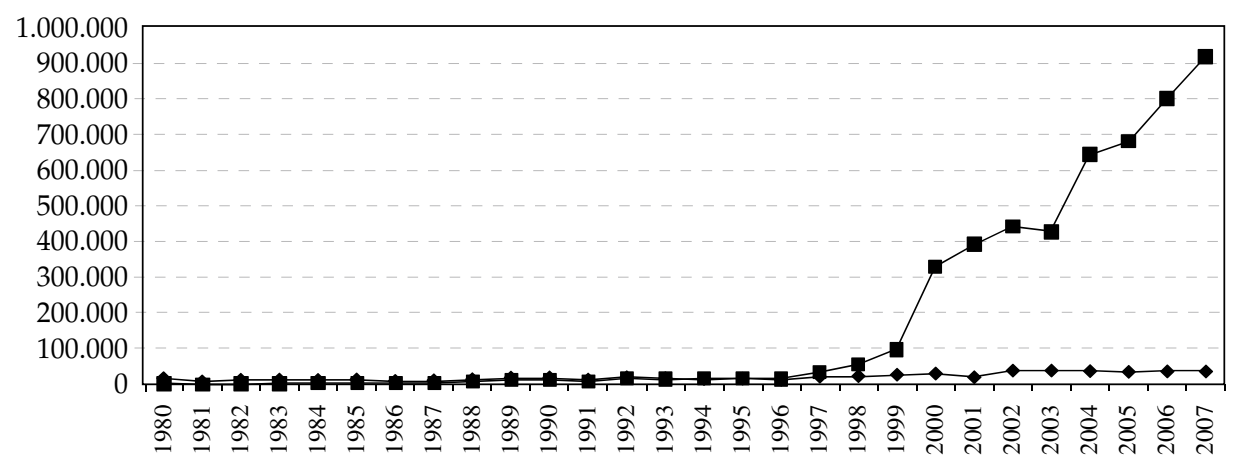

$$
\rightarrow \text { Españoles } \rightarrow \text { Extranjeros }
$$

Fuente: Elaboración propia basada en INE, Estadística de Variaciones Residenciales (varios años).

16 Un análisis con detalle de este proceso puede encontrarse, entre otros, en: Arango, 2004; Cebolla \& González, 2008; Zapata \& Pinyol, 2008; y García Roca \& Lacomba, 2008. 
Este fenómeno reciente, de extraordinario interés demográfico, social y económico, tiene más relevancia, si cabe, como consecuencia de la coyuntura de atonía demográfica en la que se encuentra la sociedad española a finales del siglo XX. Una transición demográfica ya finalizada y unas bajas tasas de natalidad, fecundidad y mortalidad son las principales señas de identidad de una población que, en el umbral del siglo XXI, presenta una escasa capacidad de crecimiento vegetativo, unos índices de envejecimiento elevados y en alza y, en estrecha relación con esta última cuestión, unas crecientes y preocupantes tasas de dependencia. Numerosos estudios, entre ellos los realizados por Izquierdo (2008), confirman que la inmigración ha pasado a convertirse en el primer factor de crecimiento tanto del conjunto del país como de las diferentes Comunidades Autónomas.

Si nos fijamos en el continente de procedencia, los principales lugares de origen de los inmigrantes extranjeros en los últimos años han sido Europa (sobre todo países de la UE) y el continente americano (Gráfico 2). Significativamente creciente a lo largo de los últimos años ha sido también la importancia de los flujos de entrada procedentes de países africanos, a la cabeza de los cuales se encuentra Marruecos.

Gráfico 2: Inmigraciones de extranjeros según continente de procedencia 1996-2007

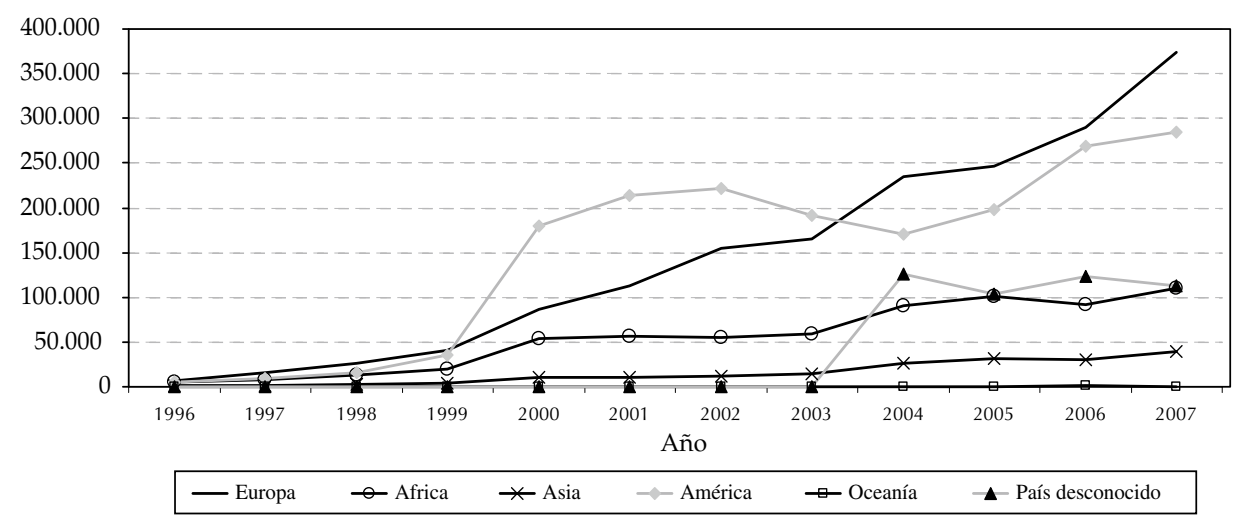

Fuente: Elaboración propia basada en INE, Estadística de Variaciones Residenciales (varios años).

Consecuencia directa de estos flujos inmigratorios tan intensos, se ha asistido en los últimos años a un crecimiento muy significativo y rápido de la población extranjera residente en el país. En la Tabla 1 se puede ver cómo los extranjeros residentes constituyen en la actualidad un colectivo de cerca de 5,6 millones de personas, pasando a representar en poco más de una década el $12 \%$ del total de la población. 
Tabla 1: Evolución de la población por nacionalidad. España 1996-2009

\begin{tabular}{lrrrc}
\hline \multirow{2}{*}{ Año } & \multicolumn{3}{c}{ Población } & $\begin{array}{c}\text { Pobl. Extranj./ } \\
\text { Pobl. Total (\%) }\end{array}$ \\
\cline { 2 - 4 } & Española & Extranjera & Total & 1,4 \\
1996 & 39.127 .080 & 542.314 & 39.669 .394 & 1,6 \\
1998 & 39.215 .566 & 637.085 & 39.852 .651 & 1,9 \\
1999 & 39.453 .206 & 748.954 & 40.202 .160 & 2,3 \\
2000 & 39.575 .912 & 923.879 & 40.499 .791 & 3,3 \\
2001 & 39.746 .185 & 1.370 .657 & 41.116 .842 & 4,7 \\
2002 & 39.859 .948 & 1.977 .946 & 41.837 .894 & 6,2 \\
2003 & 40.052 .896 & 2.664 .168 & 42.717 .064 & 7,0 \\
2004 & 40.163 .358 & 3.034 .326 & 43.197 .684 & 8,5 \\
2005 & 40.377 .920 & 3.730 .610 & 44.108 .530 & 9,3 \\
2006 & 40.564 .798 & 4.144 .166 & 44.708 .964 & 9,9 \\
2007 & 40.634 .326 & 4.482 .568 & 45.116 .894 & 11,4 \\
2008 & 40.889 .060 & 5.268 .762 & 46.157 .822 & 12,0 \\
$2009\left(^{*}\right)$ & 41.063 .259 & 5.598 .691 & 46.661 .950 & \\
\hline
\end{tabular}

Nota: $\left(^{*}\right)$ Datos provisionales.

Fuente: Elaboración propia basada en INE, Censo de Población y Padrón Municipal de Habitantes (varios años).

\section{LA ENCUESTA NACIONAL DE INMIGRANTES}

El trabajo que aquí se presenta pretende llevar a cabo una aproximación empírica al estudio de las cadenas migratorias en España a partir de los resultados obtenidos en la aplicación de la primera Encuesta Nacional de Inmigrantes (ENI) del año $2007 .{ }^{17} \mathrm{La}$ ENI es una nueva operación estadística desarrollada conjuntamente por el INE, el Grupo de Estudios Población y Sociedad de la Universidad Complutense de Madrid y el Ministerio de Trabajo y Asuntos Sociales y tiene como propósito profundizar en el análisis de la situación sociodemográfica y económica de los inmigrantes, los factores que influyen en la decisión de emigrar y sus estrategias y experiencia migratoria.

Como señalan Rodríguez \& Adam (2009), la ENI-2007 amplía sustancialmente la información estadística disponible sobre los inmigrantes, permitiendo abordar de una manera novedosa, multidimensional y dinámica aspectos muy relevantes del proceso migratorio, entre ellos el relativo a la integración social y el papel que desempeñan las redes sociales. 
Para la elaboración de la ENI fueron realizadas 15.465 entrevistas a inmigrantes localizados a partir de una muestra de hogares tomados del Padrón Continuo. ${ }^{18}$ Los resultados son representativos a nivel nacional gracias al empleo de factores de elevación y ponderación correspondientes al marco muestral. Es importante aclarar que la ENI define como inmigrante a las personas con 16 y más años nacidas en el extranjero y que viven en España (o tiene intención de hacerlo) desde hace un año o más tiempo. Se excluye el caso de los españoles de nacimiento nacidos fuera de España que en el año de llegada a España tenían menos de dos años, los retornos de españoles de nacimiento (nacidos en España) y a los extranjeros nacidos en España y se incluyen los nacidos fuera de España con nacionalidad española desde el nacimiento ${ }^{19}$.

La ENI estimó que a la fecha de referencia de la encuesta había en España 4.526.522 residentes nacidos en el extranjero y mayores de 15 años, que venían a representar un $12 \%$ del total de la población con más de 15 años residente en el país. En la Tabla 2 se ofrece la distribución de los inmigrantes por lugar de nacimiento. Como se puede observar, el colectivo más significativo es el procedente de países americanos sin EE.UU. y Canadá $(39,5 \%)$, seguido de los que tienen su origen en algún país de la UE $27(33 \%)$. Por países, a la fecha considerada era predominante la población procedente de Rumanía y Bulgaria (11,7\%) y Marruecos (11,9\%), consecuencia directa de cómo ha sido la composición predominante de los flujos inmigratorios con destino España en los últimos años.

La estructura por sexo y edad de la población inmigrante está reflejada en el Gráfico 3. Como se aprecia, hay un predominio general de población masculina (las mujeres representan un $47,8 \%$ de la población), que se explica por la desigual distribución de los efectivos masculino y femenino en las diferentes comunidades de origen y el importante peso dentro del total de inmigrantes de los procedentes de países latinoamericanos, que son los mayoritariamente compuestos por mujeres. Este desequilibrio también se explica por la escasa antigüedad de las corrientes inmigratorias, hecho que se va progresivamente corrigiendo a medida que los inmigrantes se asientan en el país receptor y se va procediendo a los procesos de reagrupación familiar y/o se constituyen nuevas familias. El hecho más significativo respecto de la distribución de la población por edad es la elevada proporción que representan los adultos jóvenes, con edades comprendidas entre los 20 y los 40 años. En definitiva, la estructura por sexo y edad de la población inmigrante es propia de un proceso inmigratorio reciente y refleja bien las razones principales que explicaron en origen el cambio en el lugar de residencia, mayoritariamente económicas y laborales, como también confirman los datos de la ENI. 
Tabla 2: Inmigrantes según país de nacimiento

\begin{tabular}{lrr}
\hline & Inmigrantes & Porcentaje \\
\hline Total & $\mathbf{4 . 5 2 6 . 5 2 2}$ & $\mathbf{1 0 0 , 0}$ \\
Países europeos sin España & $\mathbf{1 . 7 2 1 . 4 7 5}$ & $\mathbf{3 8 , 0}$ \\
UE 27 sin España & 1.507 .115 & 33,3 \\
Reino Unido & 269.470 & 6,0 \\
Alemania & 159.922 & 3,5 \\
Rumania y Bulgaria & 530.786 & 11,7 \\
Resto UE 27 sin España & 546.938 & 12,1 \\
Resto de países europeos sin España & 214.360 & 4,7 \\
Países africanos & 767.588 & $\mathbf{1 7 , 0}$ \\
Marruecos & 539.773 & 11,9 \\
Resto de países africanos & 227.815 & 5,0 \\
Países americanos & $\mathbf{1 . 8 2 1 . 2 1 5}$ & 40,2 \\
EE.UU. y Canadá & 33.523 & 0,7 \\
Países americanos sin EE.UU. ni Canadá & 1.787 .691 & 39,5 \\
Ecuador & 371.743 & 8,2 \\
Colombia & 299.479 & 6,6 \\
Bolivia & 157.732 & 3,5 \\
Argentina & 231.630 & 5,1 \\
Resto de países americanos sin EE.UU. ni Canadá & 727.107 & 16,1 \\
Países asiáticos y Oceanía & $\mathbf{2 1 6 . 2 4 4}$ & $\mathbf{4 , 8}$ \\
China & 53.887 & 1,2 \\
Resto de países asiáticos y de Oceanía & 162.357 & 3,6 \\
\hline
\end{tabular}

Fuente: Elaboración propia basada en Instituto Nacional de Estadística. ENI 2007.

Gráfico 3: Estructura por sexo y edad de la población inmigrante

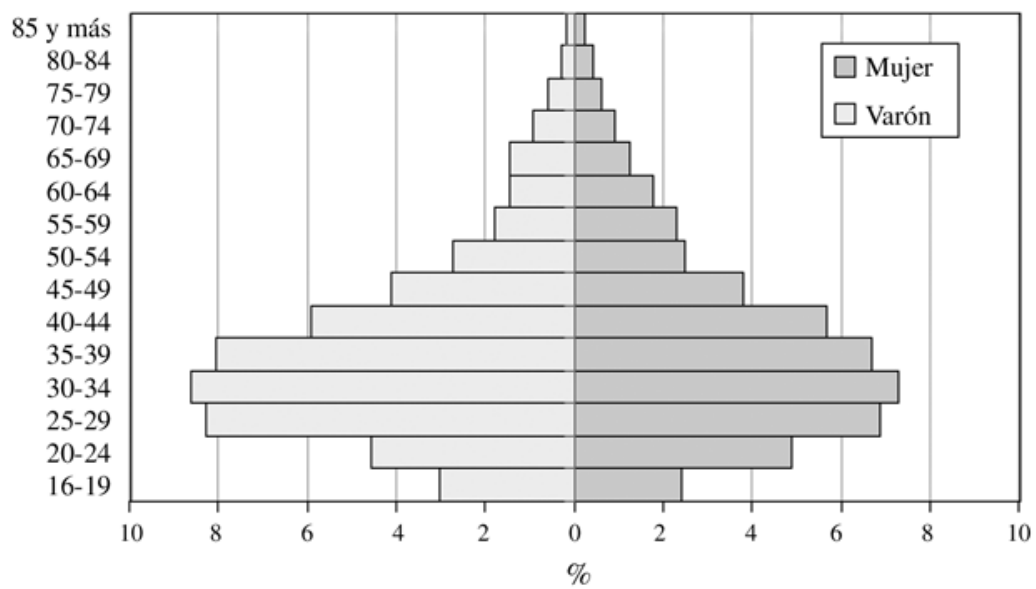

Fuente: Elaboración propia basada en Instituto Nacional de Estadística. ENI 2007. 
La Tabla 3 permite observar la reciente cronología del fenómeno inmigratorio. La inmensa mayoría $(70 \%)$ de los inmigrantes han llegado a partir de 1997, siendo especialmente elevado el número de ellos que lo hicieron en los últimos 6 años (41\% entre 2002 y 2007).

Tabla 3: Inmigrantes según año de llegada

\begin{tabular}{lccccccc}
\hline & Total & $\begin{array}{c}\text { Entre } \\
2002 \mathrm{y} \\
2007\end{array}$ & $\begin{array}{c}\text { Entre } \\
1997 \mathrm{y} \\
2001\end{array}$ & $\begin{array}{c}\text { Entre } \\
1992 \mathrm{y} \\
1996\end{array}$ & $\begin{array}{c}\text { Entre } \\
1987 \mathrm{y} \\
1991\end{array}$ & $\begin{array}{c}1986 \mathrm{y} \\
\text { anteriores }\end{array}$ & $\begin{array}{c}\text { No } \\
\text { sabe }\end{array}$ \\
\hline Inmigrantes & 4.526 .522 & 1.863 .444 & 1.309 .751 & 319.665 & 269.451 & 694.807 & 69.404 \\
Porcentaje & $100,0 \%$ & $41,2 \%$ & $28,9 \%$ & $7,1 \%$ & $6,0 \%$ & $15,3 \%$ & $1,5 \%$ \\
\hline
\end{tabular}

Fuente: Elaboración propia basada en Instituto Nacional de Estadística. ENI 2007.

\section{ANÁLISIS DE LOS INDICADORES SOBRE CADENAS MIGRATORIAS DE LA ENCUESTA NACIONAL DE INMIGRANTES}

El análisis de los datos realizado en el presente artículo se desarrolla respecto de algunas variables consideradas en la ENI que tienen relación con el paradigma relacional como explicativo de la inmigración en España. Así, se consideran como factores relevantes en dicho proceso a las cadenas migratorias, en tanto que proporcionan recursos (de información, de ayuda, etc.) al inmigrante en el momento de viajar y una vez instalados en la sociedad receptora, y mantienen los vínculos con la sociedad de origen, de modo que los protagonistas de la migración se convierten en potenciales enlaces facilitadores de nuevas migraciones. En este sentido, las variables que han sido seleccionadas y que se analizan a continuación son las siguientes:

- Contactos previos del inmigrante.

- Influencia de los contactos en la decisión de viajar.

- Envío de remesas.

- Contactos del inmigrante en el país de origen.

- Intención de traer familiares.

\subsection{Los contactos previos del inmigrante}

La ENI nos permite una primera aproximación al fenómeno de las cadenas migratorias a partir de la información que proporciona sobre los contactos previos del inmigrante con personas residentes en el territorio español. Al respecto hay que señalar que la mayoría de los llegados a España después del año 1990 (un 79,4\%) tuvo contactos previos (Gráfico 4). Este dato da cuenta de la relevancia para el inmigrante de las redes de acogida a la hora de emprender la aventura migratoria, pues no sólo permiten reducir la incertidumbre propia del momento, sino que también facilitan el proceso de acogida e integración en la sociedad de destino. 
Gráfico 4: Inmigrantes llegados después del año 1999 según contacto previo en España

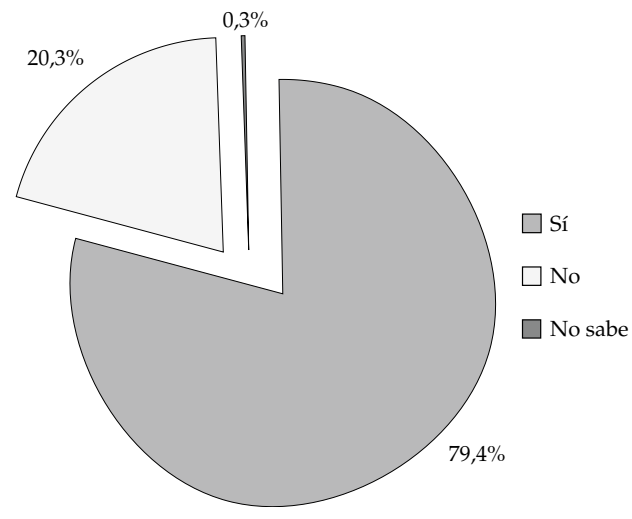

Fuente: Elaboración propia basada en Instituto Nacional de Estadística. ENI 2007.

Si tenemos en cuenta el año de llegada (Gráfico 5) se observa una tendencia creciente en dicho comportamiento, siendo cada vez mayor el porcentaje de los inmigrantes que afirmaron poseer un contacto previo a su llegada al país, hasta alcanzar el $86 \%$ en el período 2005 y posteriores.

Gráfico 5: Inmigrantes llegados a España desde 1990 que poseían contactos previos, según año de llegada (\%)

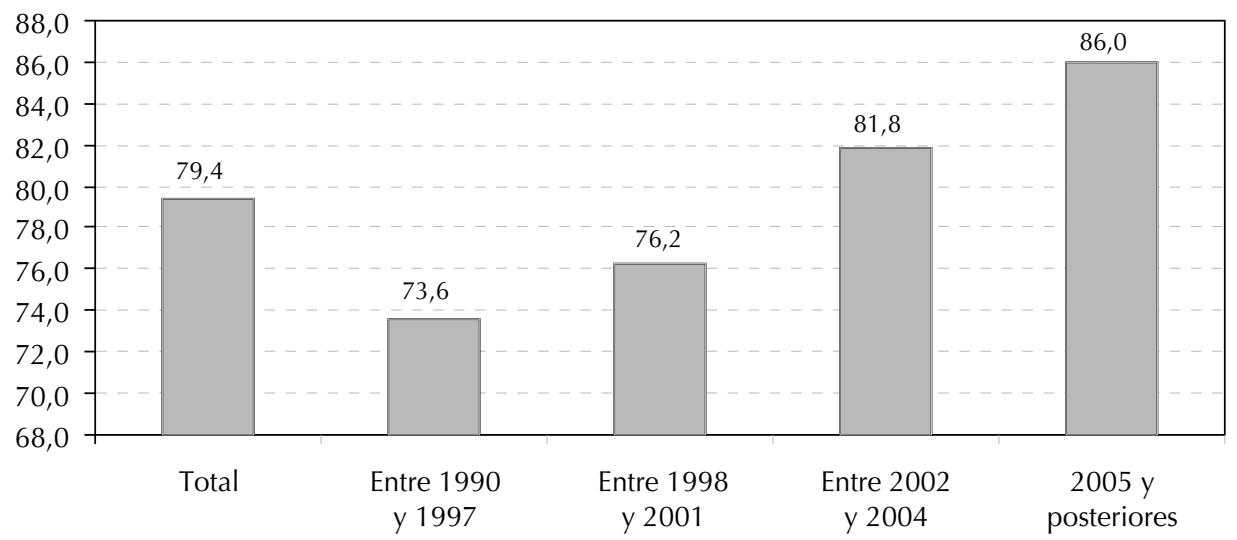

Fuente: Elaboración propia basada en Instituto Nacional de Estadística. ENI 2007.

Al desagregar estos resultados por zonas geográficas, nos encontramos con las distribuciones por grupos de países recogidas en el Gráfico 6. No obstante es posible desagregar además por los países de más alta frecuencia en cada grupo. 
Gráfico 6: Inmigrantes con contacto previo en España, por zona geográfica de origen $(\%)$

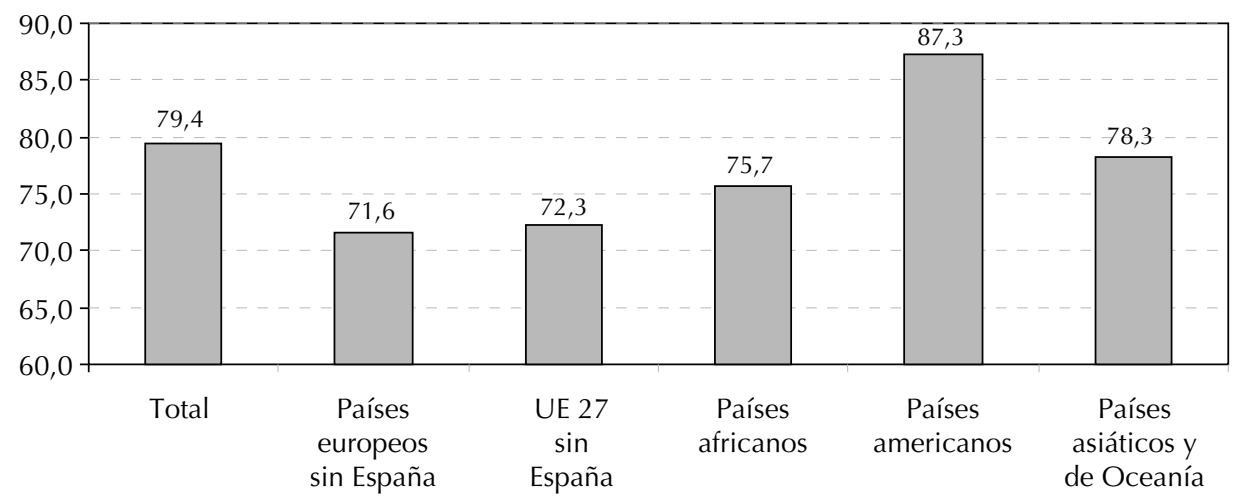

Fuente: Elaboración propia basada en Instituto Nacional de Estadística. ENI 2007.

Con la introducción de la variable geográfica, se observa claramente que son los inmigrantes de países americanos $(87,3 \%)$ los que afirman en un más alto porcentaje que tenían un contacto en el momento de su llegada a España. Al analizar en detalle los países americanos, se observa que los inmigrantes estadounidenses y canadienses con un $91,4 \%$ del total de ciudadanos de aquellos países afirmaban poseer un contacto al momento de su llegada al país, seguidos por los inmigrantes ecuatorianos con un $87,6 \%$ y los inmigrantes colombianos con un 86,7\% confirmaban una situación similar.

En primera instancia, el alto porcentaje registrado para esta consulta por los ciudadanos de EE.UU. y Canadá resulta lógico debido a la barrera idiomática que se presenta para estos inmigrantes en España, siendo muy importante para "tirar" de la cadena migratoria el hecho de disponer de algún contacto, que puede comunicarse en su idioma nativo y les ayude en el proceso de instalación en el país.

No obstante, si se compara con los ciudadanos del Reino Unido, que por efectos del idioma pudieran estar en la misma situación, se observa un comportamiento absolutamente diferente y los británicos son los únicos que señalan en un $54 \%$ que NO poseían un contacto en España al momento de su llegada, demostrando entonces que en el caso de norteamericanos y canadienses además del aspecto idiomático, es importante tener un contacto en España por aspectos culturales y sociales que los ayude con la adaptación en el país.

Estos altos porcentajes de existencia de un contacto al momento de la llegada a España, con excepción de los ciudadanos del Reino Unido analizado anteriormente, muestran una importante contribución de la inmigración a la creación de capital social en el nivel meso, vale decir con familiares, amigos o conocidos del barrio, con los cuales se mantienen o fortalecen relaciones sociales que no sólo motivan la inmigración sino que también abren espacios y contactos hacia redes laborales, educacionales o sociales de los recién llegados al país. 
Al desagregar por tramos de edad (Gráfico 7), en los extremos se observan los porcentajes más altos de inmigrantes que poseían algún contacto en el país al momento de llegar. En el caso del tramo 16 a 19 años de edad, el 89,4\% confirma tal situación y, en el caso del tramo 85 y más años de edad, el 100\% de los inmigrantes tenía algún contacto a su llegada a España.

En el resto de los tramos etarios intermedios, con edades comprendidas entre los 20 y los 69 años de edad, el porcentaje de inmigrantes que afirma haber tenido algún contacto al momento de su llegada a España muestra un comportamiento decreciente a medida que aumenta la edad.

Gráfico 7: Inmigrantes con contacto previo en España, por edad (\%)

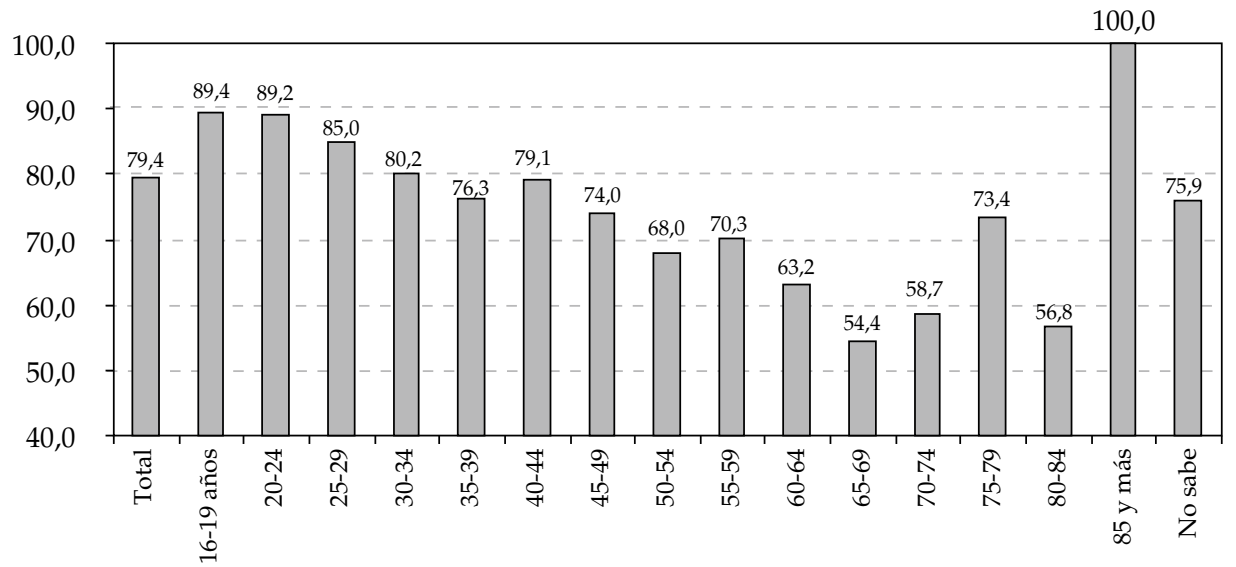

Fuente: Elaboración propia a partir de los datos de INE, ENI 2007.

De esta manera, se confirma la influencia del primo-inmigrante en el desarrollo de la inmigración hacia España (Arango, 2004), donde es posible confirmar que las cadenas migratorias ya han pasado a una fase de desarrollo posterior de reagrupación familiar, incluyendo en algunos casos hasta los padres de los primo-inmigrantes como lo señala el análisis desagregado por edades.

\subsection{La influencia de los contactos en la decisión de emigrar}

Otro aspecto importante de analizar en el desarrollo de las cadenas migratorias es la influencia de conocidos y familiares para tomar la decisión de emigrar desde el país de origen, siendo además un elemento fundamental para la acumulación de capital social, especialmente por las expresiones de confianza, reciprocidad y comunicación entre las distintas personas que forman parte de la cadena. La ENI también aporta información al respecto, indicando de forma agregada que algo más de la mitad de los encuestados (un 52,3\%) reconocen la influencia de algún paisano con experiencia migratoria previa sobre su decisión de venir a España. 
Si tenemos en cuenta el lugar de origen de los inmigrantes que sí se han visto influidos por personas conocidas (Gráfico 8), se observan diferencias significativas entre las grandes áreas, siendo el conjunto de los países del continente americano aquéllos en que es más frecuente la influencia de los contactos previos en la decisión de emigrar.

Gráfico 8: Influencia de algún conocido de su país de nacimiento que ya había emigrado para venir a España, según el origen del inmigrante (\%)

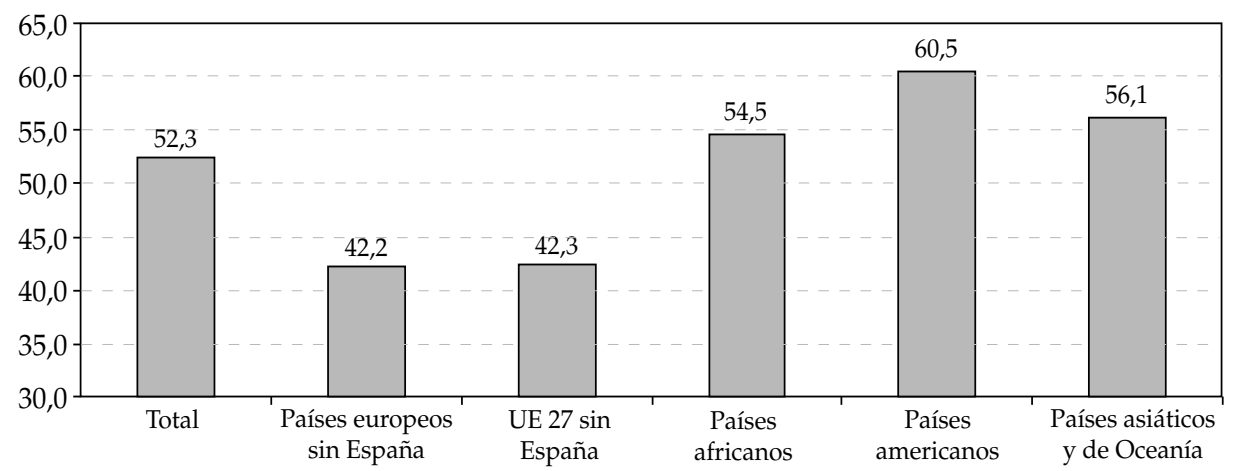

Fuente: Elaboración propia basada en Instituto Nacional de Estadística. ENI 2007.

Al desagregar por países, nos encontramos con que los ciudadanos rumanos y búlgaros señalan en un 65,7\% que sí tuvieron la influencia de algún conocido de su país para viajar a España, mientras que en el caso de alemanes $(26,9 \%)$ y ciudadanos del Reino Unido $(24,7 \%)$ muestran un comportamiento minoritario al momento de recibir influencia de alguien de su propio país viviendo en España, para tomar la decisión de viajar.

Respecto de los inmigrantes africanos, los ciudadanos marroquíes $(58,1 \%)$ muestran un comportamiento levemente positivo hacia esta influencia, a pesar de que la inmigración de ciudadanos africanos es tristemente célebre en España por los continuos intentos por ingresar al país a través de embarcaciones ligeras denominadas "pateras".

En relación con los países americanos, el caso que muestra mayor influencia de los conocidos para viajar a España es el de los ciudadanos ecuatorianos con un 70,9\% y los colombianos con un $67,9 \%$ de respuestas positivas, mostrando la mayor fuerza de la cadena migratoria en cuanto a la influencia para tomar la decisión de viajar por parte de algún conocido.

Finalmente, en el caso de los países asiáticos sólo se encuentran desagregados los datos de China, que con un $64,4 \%$ también muestra una importante fuerza de la cadena migratoria respecto de los primeros inmigrantes, que incentivan y motivan a otros para tomar la decisión de viajar. 


\subsection{El envío de remesas}

El envío de remesas es una de las consecuencias económicas tradicionales de los procesos migratorios, especialmente en los casos en que la situación económica del inmigrante es mejor que la que existe en su país de origen. El envío de remesas es un indicador de la transnacionalidad de las redes de los inmigrantes y de la importancia que tienen los vínculos familiares, pues es la familia que queda en el país de origen el principal destinatario de estos recursos.

Gráfico 9: Inmigrantes que envían remesas a su país de origen

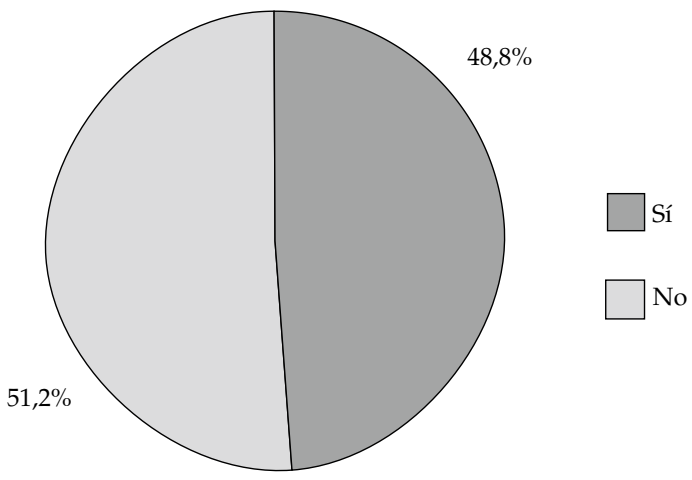

Fuente: Elaboración propia basada en Instituto Nacional de Estadística. ENI 2007.

En el gráfico anterior se observa que el $51,2 \%$ de los inmigrantes encuestados no envía remesas a los familiares, amigos o conocidos que han quedado en sus respectivos países de origen, situación que puede originarse en base a distintos factores tales como mala situación económica del inmigrante, ausencia de personas en su país de origen a las cuales enviar remesas, situación legal del inmigrante en el país en el que reside, entre otros factores que pueden desmotivar o impedir el envío de remesas. Pero no se puede obviar ese otro $48,8 \%$ de personas que sí lo hacen, y que suponen un porcentaje ciertamente representativo del total de los inmigrantes asentados en España.

En el análisis del envío de remesas es muy importante considerar la frecuencia con la que esta acción es desarrollada, así como respecto de quienes son los destinatarios de dichos envíos. En el Gráfico 10 se observa claramente que casi la mitad de los inmigrantes que envían remesas a sus países de origen $(48,5 \%)$ lo hacen al menos una vez cada mes y un $18,5 \%$ lo hace trimestralmente, evidenciándose un flujo bastante habitual en los envíos. 
Gráfico 10: Inmigrantes en España según frecuencia en el envío de remesas a su país de origen $(\%)$

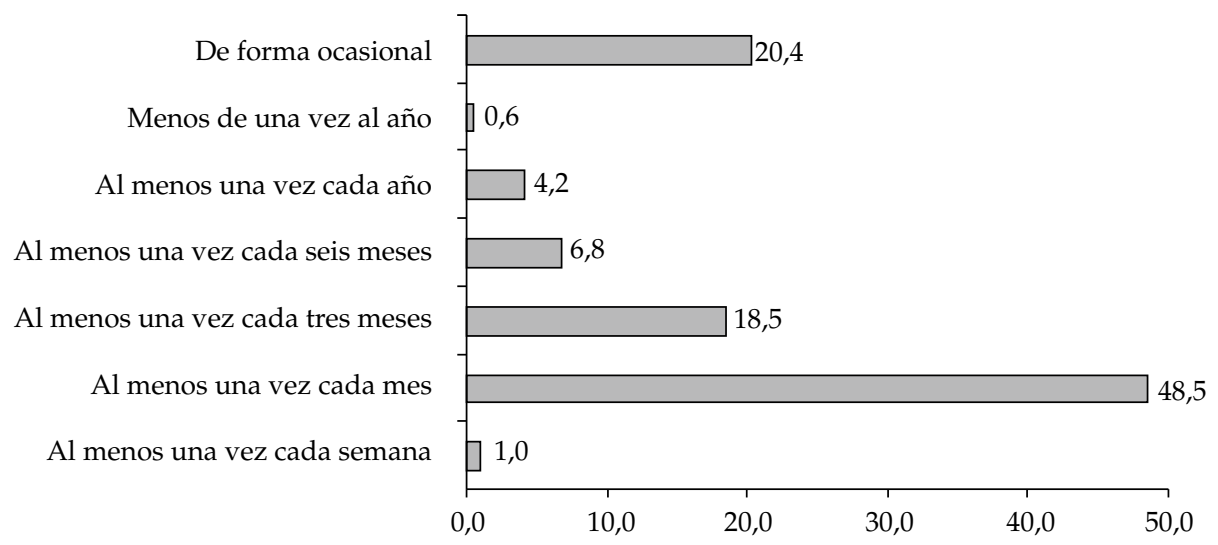

Fuente: Elaboración propia basado en Instituto Nacional de Estadística. ENI 2007.

Al analizar los destinatarios de las remesas, poniendo especial atención respecto de quiénes son los receptores de los envíos, es posible comprobar el grado en el que las cadenas migratorias incorporan miembros de la familia. En la Tabla 2 se recoge la frecuencia con la que los inmigrantes que envían remesas eligen como destinatario de las mismas a un pariente más o menos cercano y/o a otras personas y/o instituciones, según el lugar de origen del inmigrante.

Como se puede observar, los padres son en todos los casos los principales destinatarios de estos recursos, lo que se explica bien habida cuenta de la edad media predominante de los inmigrantes (adultos jóvenes) (Tabla 4). Especialmente importante resulta este grupo como destinatario de las remesas para el colectivo de inmigrantes de origen africano (el 73,7\% de los encuestados que envían remesas señala a sus padres como uno de los destinatarios de las mismas). Los hijos y los hermanos son, aunque a distancia de los padres, los siguientes destinatarios principales de las remesas enviadas por los inmigrantes españoles, destacando de nuevo el caso de los inmigrantes africanos, que indican en una mayor proporción a los hermanos que a los hijos.

Los resultados presentados en el cuadro anterior están obviamente condicionados por los procesos de reagrupación familiar. Así, en la medida en que un inmigrante haya podido venir o traer ya a su familia, en ese grado nos encontraremos con que no envía remesas y/o los diferentes parientes no se encuentran entre el conjunto de los destinatarios de las mismas.

Al realizar un análisis desagregado por países, nos encontramos con que en los casos de los inmigrantes del Reino Unido y Alemania, ninguno de los encuestados envía remesas de dinero al esposo/esposa/pareja, lo que es indicativo de que inmigraron juntos hasta España o son personas solas, que no tienen ningún vínculo marital o, sencillamente, de 
Tabla 4: Inmigrantes según destinatario de las remesas enviadas a su país de origen y país de origen

\begin{tabular}{|c|c|c|c|c|c|}
\hline & Total & $\begin{array}{c}\text { Países } \\
\text { europeos } \\
\text { sin España }\end{array}$ & $\begin{array}{l}\text { Países } \\
\text { africanos }\end{array}$ & $\begin{array}{c}\text { Países } \\
\text { americanos }\end{array}$ & $\begin{array}{c}\text { Países } \\
\text { asiáticos } \\
\text { y de } \\
\text { Oceanía }\end{array}$ \\
\hline $\begin{array}{l}\text { Esposo/Esposa/ } \\
\text { Pareja }\end{array}$ & $10,6 \%$ & $7,4 \%$ & $20,4 \%$ & $8,2 \%$ & $13,1 \%$ \\
\hline Padres & $62,4 \%$ & $50,4 \%$ & $73,7 \%$ & $59,5 \%$ & $63,7 \%$ \\
\hline Hijos & $25,8 \%$ & $24,8 \%$ & $17,6 \%$ & $29,6 \%$ & $23,7 \%$ \\
\hline Hermanos & $22,5 \%$ & $17,6 \%$ & $30,4 \%$ & $21,9 \%$ & $23,6 \%$ \\
\hline Otros parientes & $13,8 \%$ & $15,2 \%$ & $9,1 \%$ & $14,8 \%$ & $15,3 \%$ \\
\hline $\begin{array}{l}\text { Otras personas no } \\
\text { familiares/Instituciones }\end{array}$ & $3,0 \%$ & $4,0 \%$ & $1,6 \%$ & $3,0 \%$ & $3,0 \%$ \\
\hline
\end{tabular}

Nota: Inmigrantes que sí envían remesas.

Fuente: Elaboración propia basada en Instituto Nacional de Estadística. ENI 2007.

que sus parientes en la sociedad de origen no tienen ninguna necesidad económica. Los inmigrantes de estos países envían dinero fundamentalmente a los hijos, aunque menos de la mitad de los encuestados tiene este destino para sus remesas.

En el caso de rumanos y búlgaros, el principal destino de las remesas son los padres, a los que el 63\% de los encuestados de estas nacionalidades los identificó como los receptores de sus remesas, lo que permite suponer un nivel de reagrupación familiar importante para los inmigrantes rumanos y búlgaros, quienes en forma minoritaria dejaron de enviar dinero a sus cónyuges o hijos porque ya viven con ellos en España.

Respecto de los países africanos, los inmigrantes marroquíes identifican como su principal destino de sus remesas a los padres, ya que el 77\% de los encuestados de aquel país los señala como los principales receptores del dinero enviado a su país, siendo mencionados en menor magnitud los cónyuges e hijos, quedando en evidencia una situación similar a la de rumanos y búlgaros, por ende un avance en la cadena migratoria importante desde el punto de vista de la reagrupación familiar.

Para los países americanos, en el caso de estadounidenses y canadienses la situación resulta absolutamente diferente a los inmigrantes europeos y africanos, ya que el principal destino de las remesas en este caso son exclusivamente los padres y otras personas no familiares o instituciones, siendo este último el principal destino de los encuestados de los países de Norteamérica.

Resulta interesante destacar que ninguno de los inmigrantes estadounidenses y canadienses residentes en España consultados en la encuesta envía remesas ni a los cónyuges, hijos, hermanos ni otro tipo de parientes, lo que a diferencia del caso de los rumanos, búlgaros o marroquíes no es necesariamente señal de reagrupación familiar, sino de ausencia de necesidad de recursos por parte de los parientes residentes en el país de origen. 
La hipótesis de la reagrupación familiar gana fuerza en el caso de los inmigrantes provenientes de Sudamérica: los inmigrantes ecuatorianos (64\%), colombianos (61\%), argentinos (57\%) y bolivianos (51\%) señalan como el principal destino de sus remesas a los padres, siendo menor el nivel de identificación del cónyuge o los hijos como el destino de las remesas, lo que hace pensar en un mayor desarrollo de la cadena migratoria en estos países.

En el caso de los países asiáticos y oceánicos, los inmigrantes chinos señalan como el principal destino de sus remesas a los padres en un $61 \%$ de los casos, y cónyuges e hijos son identificados en porcentajes menores como el destino de las remesas.

\subsection{Los contactos de los inmigrantes en el país de origen}

Otro aspecto considerado en la ENI y relacionado con el capital social de los inmigrantes es el relativo al mantenimiento de los lazos familiares y/o de amistad con personas que residen en su país de origen, lo que también puede ser visto como indicativo de la existencia de cadenas migratorias.

Del total de inmigrantes consultados, el $90 \%$ afirma mantener contacto con sus familiares y amigos, que han quedado atrás en el país de nacimiento (Gráfico 11). De este modo, el inmigrante ya residente en el país de acogida se transforma a su vez en un contacto en España para posibles nuevos inmigrantes, que potencialmente darán continuidad a las cadenas de inmigrantes en el futuro.

Gráfico 11: Inmigrantes según contacto con sus familiares o amigos en su país de nacimiento

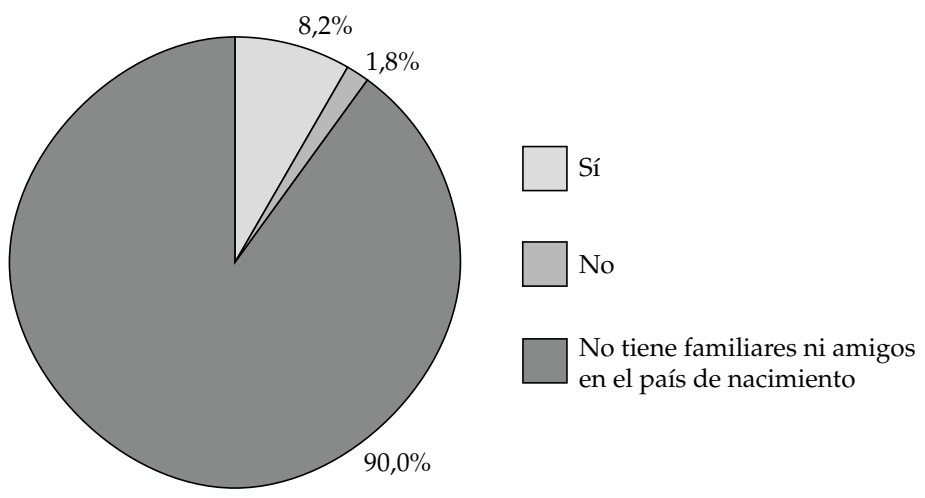

Fuente: Elaboración propia basada en Instituto Nacional de Estadística. ENI 2007.

Resulta relevante analizar por zona geográfica este altísimo porcentaje de inmigrantes que mantienen contacto con sus familiares, amigos y conocidos en su país de nacimiento, para determinar si esta conducta varía dependiendo del continente o país del cual provienen los inmigrantes en España. En el Gráfico 12 se observa que son los inmigrantes de países 
americanos quienes registran los mayores resultados, con respecto a los otros cuatro continentes presentes en la encuesta con más del $93 \%$ de inmigrantes, confirmando la mantención de vínculos con el país de origen. El caso opuesto es el del colectivo africano, que es el que en menor medida mantiene dichos vínculos.

Gráfico 12: Inmigrantes con contacto con sus familiares y amigos en su país de nacimiento, por zona geográfica de origen $(\%)$

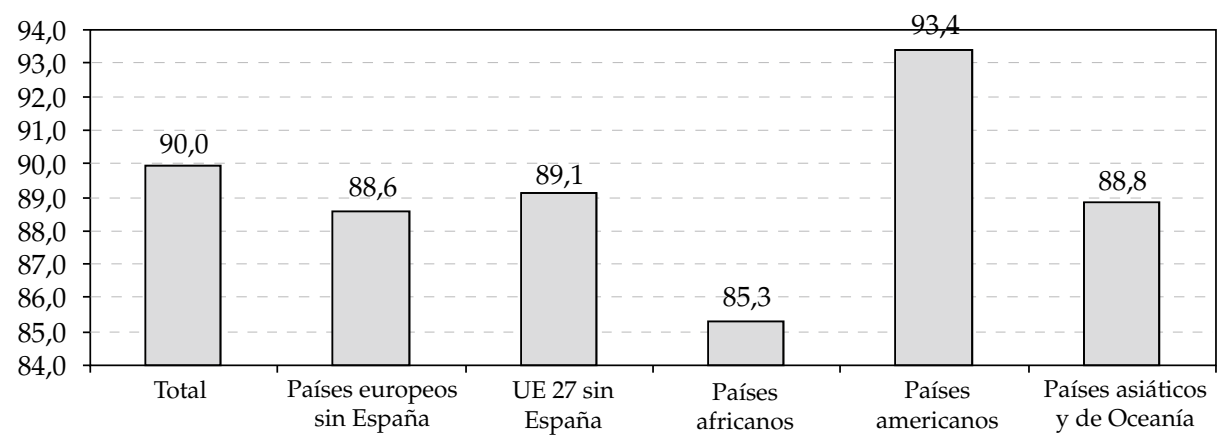

Fuente: Elaboración propia basada en Instituto Nacional de Estadística. ENI 2007.

En un nivel de desagregación más específico por países, en Europa los inmigrantes del Reino Unido con un $94,3 \%$ y los inmigrantes rumanos y búlgaros con un $97,2 \%$ registran los niveles más altos.

En Asia y Oceanía, los inmigrantes chinos señalan en un 95,8\% mantener contacto con familiares y amigos en su país, siendo especialmente sensible en el caso de los inmigrantes de este país, el apoyo que encuentran en el uso de las nuevas tecnologías de información y comunicación, para mantener un contacto más permanente en un tan alto porcentaje de los casos.

Finalmente, en América son los inmigrantes ecuatorianos con un 97,9\%, los bolivianos con un $97,9 \%$ y los colombianos con un $96,7 \%$, quienes señalan mantener un mayor contacto con familiares y amigos en sus respectivos países.

\subsection{La intención de traer familiares}

Un último indicador de la existencia de cadenas migratorias que hemos seleccionado desde la ENI 2007, se refiere a la intención de los inmigrantes de traer a sus familiares que permanecen en sus respectivos países de origen, como expresión de la continuidad del proyecto migratorio mediante la cadena ya iniciada. En el Gráfico 13 se observa como uno de cada cuatro inmigrantes encuestados tiene la intención de dar continuidad al proceso migratorio en los próximos años, trayendo alguno de sus familiares aún residentes en su país de origen. 
Gráfico 13: Inmigrantes según su intención de traer familiares

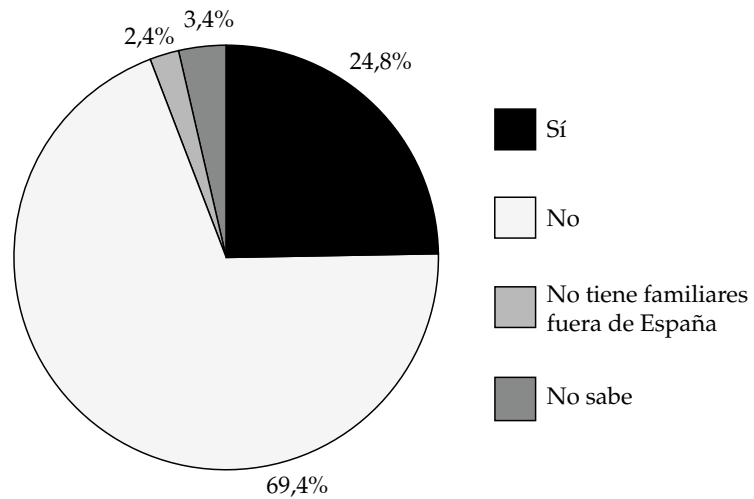

Fuente: Elaboración propia a partir de los datos de INE, ENI 2007.

Es evidente observar que casi el 70\% de los inmigrantes consultados declara que no tiene intención de traer familiares, lo que como se ha señalado en análisis anteriores puede ser explicado por diferentes causas relacionadas por ejemplo con el término de los procesos de reagrupación familiar dado que los familiares directos (padres, cónyuges e hijos) ya se han reunido con el primo-inmigrante; las mayores dificultades administrativas para ingresar a Europa; y muy especialmente los efectos de la crisis económica que comenzaban a visualizarse en España al momento de realizar la consulta, especialmente en el sector de la construcción en el país, uno de los que concentran la mayor tasa de contratación de mano de obra inmigrante en el país hasta antes de la crisis.

\section{CONCLUSIONES}

El presente trabajo se ha centrado desde un punto de vista empírico en la identificación y análisis de algunos indicadores de cadenas migratorias en España a partir de los datos de la ENI. Desde una perspectiva teórica, se sostiene que el concepto de cadena migratoria, aún resultando muy próximo al de redes sociales, se distingue de este segundo en varios aspectos. En primer lugar, cabe señalar que las cadenas migratorias están especialmente vinculadas al período de tiempo que media entre la decisión de partir del emigrante, la elección del destino y el asentamiento en la nueva sociedad.

En segundo lugar, en el caso de las cadenas migratorias están especialmente sobrerrepresentadas las relaciones informales con familiares y conocidos, por lo que constituyen un tipo particular de redes migratorias. Asimismo, las cadenas migratorias tienen una clara dimensión interespacial, al vincular entre sí a potenciales migrantes con personas que ya han emigrado y que funcionan como informantes y soporte de los anteriores.

Por último, señalar que las cadenas migratorias constituyen un primer eslabón para el desarrollo en la sociedad de destino de redes sociales amplias y complejas, siempre y 
cuando los vínculos relacionales iniciales de carácter mayoritariamente familiar o de amistad se amplíen y extiendan hacia otros grupos y organizaciones o instituciones vinculadas o no con la inmigración.

Los resultados proporcionados por la ENI nos permiten observar claramente la presencia e importancia de las cadenas migratorias para el caso de la inmigración reciente en España. Especialmente en el caso de los inmigrantes latinoamericanos y de Europa del Este se constata una clara influencia de los familiares y conocidos para tomar la decisión de partir de su lugar de origen hacia España, así como la disponibilidad de contactos en España al momento de su llegada al país.

Otro indicador que demuestra la relevancia de las cadenas migratorias en España es el envío de remesas, un vínculo económico muy frecuente en determinadas comunidades. Incluso en los casos en que no hay estos envíos de remesas o en los que los destinatarios son unos tipos de parientes y no otros, podemos suponer la existencia de cadenas migratorias vía el reagrupamiento familiar. Así, y a modo de hipótesis, se puede interpretar que el que buena parte de las remesas que europeos, africanos y latinoamericanos se dirijan mayoritariamente a los padres y no al cónyuge o los hijos obedece al hecho de que éstos últimos se encuentran ya reunidos con el inmigrante en España.

El análisis de los indicadores de cadenas migratorias seleccionados de entre las variables de la ENI nos lleva a concluir que éstas han tenido y tienen un gran protagonismo en el desarrollo de la inmigración en España desde 1975 a la fecha. Finalmente señalar que desde la aplicación de la ENI han cambiado drásticamente en España muchas de las condiciones económicas que en su momento pudieron resultar decisivas para la elección de este país como destino de muchos inmigrantes.

La fuerte crisis económica y financiera existente a nivel mundial, pero que afecta con especial dureza al pueblo español -especialmente al sector de la construcción y en el ámbito industrial-, las nuevas políticas del Gobierno de España para controlar los flujos migratorios, que se traducen en un endurecimiento de los requisitos y procedimientos de ingreso y reagrupación familiar de los inmigrantes al país, así como las políticas de incentivo al retorno que el actual mandato del Presidente Rodríguez Zapatero está impulsando recientemente están modificando sin duda la intensidad de los flujos inmigratorios y operarán también aumentando los retornos de extranjeros a su país de origen. Las cadenas migratorias recobran si cabe más protagonismo en coyunturas como la actual en la que resulta más necesario que nunca el apoyo y la solidaridad de los más próximos.

\section{REFERENCIAS}

Aparicio, Rosa y Tornos, Andrés. 2005. Las redes sociales de los inmigrantes extranjeros en España. Un estudio sobre el terreno. Madrid: Ministerio de Trabajo y Asuntos Sociales.

Arango, Joaquín. 2004. “La inmigración en España a comienzos del siglo XXI” En Informe sobre la situación demográfica en España. Coordinado por J. Leal. Madrid: Fundación Fernando Abril Martorell, 161-186.

Blanco, Cristina. 2000. Las migraciones contemporáneas. Madrid: Alianza. 
Cebolla, Héctor y González, Amparo. 2008. La inmigración en España (2000-2007). De la gestión de flujos a la integración de los inmigrantes. Madrid: Centro de Estudios Políticos y Constitucionales.

Colectivo IOÉ. 1999. "La inmigración extranjera en España". En La inmigración extranjera en España. Los retos educativos. Coordinado por E. Aja. Barcelona: Fundación La Caixa, 13-68.

Colectivo IOÉ. 2003. "La sociedad española y la inmigración extranjera". Papeles de Economía Española 98: 16-31.

Faist, Thomas. 2000. The volume and dynamics of international migration and transnational social spaces. New York: Oxford University Press.

García Roca, Joaquín y Lacomba, Joan. 2008 (Eds.). La inmigración en la sociedad española. Una radiografía multidisciplinar. Barcelona: Bellaterra.

González, Amparo. 2008. Estrategias familiares y laborales en la emigración. Reagrupación familiar, elección de parejas y empleo de los inmigrantes en el país de destino. Madrid: Consejo Económico y Social.

Gurak, Douglas y Caces, Fe. 1998. "Redes migratorias y la formación de sistemas de migración". En Cruzando fronteras. Migraciones en el sistema mundial, compilado por G. Malgesini. Barcelona: ICARIA, 75-110.

Instituto Nacional de Estadística. 2008. Encuesta Nacional de Inmigrantes 2007. Metodología. Madrid España. Fecha de acceso: 6 de marzo de 2009, http://www.ine.es/daco/daco42/inmigrantes/ inmigra_meto.pdf

Instituto Nacional de Estadística. 2009. Encuesta Nacional de Inmigrantes 2007: Una monografía. Madrid España. Fecha de acceso: 16 de marzo de 2009, http://www.ine.es/prodyser/pubweb/eni07/ eni07.htm

Izquierdo, Antonio. 2008. "Terremoto en los cimientos del modelo migratorio". En La inmigración en la sociedad española. Una radiografía multidisciplinar. Editado por J. García Roca y J. Lacomba. Barcelona: Bellaterra, 75-91.

López de Lera, Diego. 2006. “Panorama de la Inmigración”. En Demografía de los Extranjeros. Incidencia en el crecimiento de la población. Dirigido por A. Izquierdo. Bilbao: Fundación BBVA, 17-71.

Malgesini, Graciela y Giménez, Carlos. 2000. Guía de conceptos sobre migraciones, racismo e interculturalidad. Madrid: La Catarata.

Martínez, Raquel y Villares, María. 2006. "Contextos de llegada e instalación”. En Demografía de los Extranjeros. Incidencia en el crecimiento de la población. Dirigido por A. Izquierdo. Bilbao: Fundación BBVA, 137-235.

Massey, D., Arango, J., Hugo, G., Kouaouci, A., Pellegrino, A. \& Taylor, E. 1998. Worlds in motion: Understanding international migration at the end of the millennium. New York: Clarendon Press.

Moreno, Iván. 2007. "Los determinantes de la inmigración internacional en España y Cataluña". En Inmigración y transformación social en Cataluña. Aspectos socioeconómicos del fenómeno inmigratorio: las cuestiones relevantes. Dirigido por G. López. Bilbao: Fundación BBVA, 47-92.

Newland, Kathleen. 2006. "Las redes migratorias como recurso de desarrollo: Más allá de las remesas". En Migraciones. Nuevas modalidades en un mundo en movimiento. Editado por C. Blanco. Barcelona: Anthropos, 57-90.

Pascual de Sans, Ángels (Dir.). 2007. Redes Sociales de Apoyo. La inserción de la población extranjera. Bilbao: Fundación BBVA.

Portes, Alejandro y Böröcz, Jósef. 1998. “Migración contemporánea. Perspectivas teóricas sobre sus determinantes y sus modalidades de incorporación". En Cruzando fronteras. Migraciones en el sistema mundial. Compilado por G. Malgesini. Barcelona: ICARIA, 43-73.

Reher, D. (Dir), Cortés, L., González, F., Requena, M., Sánchez, M., Sanz, A. y Stanek, M. 2008. Informe Encuesta Nacional de Inmigrantes (ENI-2007). INE: Madrid España. Fecha de Acceso: 6 de marzo 2009, http://www.ine.es/daco/daco42/inmigrantes/informe/eni07_informe.pdf

Requena, Félix. 1991. Redes sociales y mercado de trabajo. Elementos para una teoría del capital relacional. Madrid: Centro de Investigaciones Sociológicas (CIS).

Rivas Nina, Myrna. 1995. “La participación social y las redes sociales de los inmigrantes en España: análisis desde una perspectiva psicosocial comunitaria". Cuaderno de Relaciones Laborales 6: 163-181. 
Rodríguez, Carmen y Adam, Elodie. 2009. "Estrategias y experiencia migratoria en Castilla y León". Boletín Económico de Castilla y León 18: 119-123.

Solé, Carlota (Dir.), Parella, Sonia y Cavalcanti, Leonardo. 2007. Los vínculos económicos y familiares trasnacionales. Los inmigrantes ecuatorianos y peruanos en España. Fundación BBVA: Bilbao España. Fecha de Acceso: 29 marzo 2009, http://www.fbbva.es/TLFU/dat/Informe_Fundacion_ BBVA_01_tcm269-159650.pdf

Touraine, Alain. 2005. Un nuevo paradigma para comprender el mundo de hoy. Barcelona: Paidós.

Truzzi, Oswaldo. 2008. "Exploring the concept of networks in migration processes". Tempo Social 20 (1): 199-218.

Vinuesa, J.; Zamora, F.; Génova, R.; Serrano, P. y Recaño, J. 1997. Demografía. Análisis y Proyecciones. Madrid: Síntesis.

Zapata-Barrero, Ricard y Pinyol, Gemma. 2008 (Eds.). Los gestores del proceso de inmigración. Actores y redes de actores en España y Europa. Barcelona: Fundación CIDOB.

Ricardo Gaete es Profesor Asistente en el Departamento de Ciencias Sociales de la Universidad de Antofagasta. Magíster en Gestión Pública de la Universidad Complutense de Madrid (2002), becario Erasmus Mundus en el Doctorado Procesos de Cambios Sociales en la Universidad de Valladolid.

E-mail: rgaete@uantof.cl)

Carmen Rodríguez es Profesora Titular de la Facultad de Ciencias Económicas y Empresariales de la Universidad de Valladolid, Directora del Departamento de Sociología y Trabajo Social. Doctora en Sociología de la Universidad de Valladolid (1993).

E-mail: sumaza@eco.uva.es 
